\title{
Conservatively managed tibial shaft fractures in Nottingham, UK: are pain, osteoarthritis, and disability longterm complications?
}

\author{
D C Greenwood, K R Muir, M Doherty, S A Milner, M Stevens, T R C Davis
}

\begin{abstract}
Objectives-To investigate longterm pain and disability subsequent to a tibial shaft fracture treated conservatively.

Design and setting-Subjects who had sustained a tibial shaft fracture more than 27 years ago were compared with those who had not.

Subjects-572 fracture patients (identified from the records of the plaster room) aged over 16 at the time of injury were contacted and were compared with 2285 randomly selected subjects matched for age, sex, and general practice.

Main outcome measures-Self reported knee pain; self reported GP's diagnosis of osteoarthritis; ability to climb stairs, walk 100 yards, to bend, kneel, or stoop; and SF-36 physical functioning score.

Results-Subjects were reviewed between 27 and 41 years after tibial shaft fracture (mean 35 years). Fracture patients were more likely to suffer chronic knee pain (odds ratio $1.23 ; 95 \%$ confidence interval (CI) $1.00,1.51$ ) and report being given a diagnosis of osteoarthritis by their GP (odds ratio 1.46; 95\% CI 1.08, 1.97). The ability to climb stairs, walk 100 yards, and bend, kneel, or stoop was less in the fracture group than the other subjects. The SF-36 physical function score was significantly lower in the fracture group.

Conclusions-More than 27 years after a tibial shaft fracture, subjects have more knee pain than the rest of the population. They also have greater difficulty performing everyday physical activities. The excess morbidity may be due to injury factors or treatment factors, and further research is needed to investigate this important association further.
\end{abstract}

Departments of Public Health Medicine and Epidemiology D C Greenwood K R Muir

and Orthopaedic and Fracture Surgery, University Hospital, Queen's Medical Centre, Nottingham NG7 2UH

S A Milner

M Stevens

T R C Davis

Rheumatology Unit, City Hospital, Nottingham NG5 1PB M Doherty

Correspondence to: Mr D Greenwood, Nuffield Institute for Health, 71-75 Clarendon Road, Leeds LS2 9PL.

Accepted for publication January 1997

\section{(F Epidemiol Community Health 1997;51:701-704)}

Twenty five years ago most isolated adult tibial shaft fractures were treated conservatively in a plaster cast, but nowadays many are treated operatively with internal or external fixation. Many surgeons have almost completely abandoned conservative treatment methods and some even consider them unethical. ${ }^{1}$ This change in fracture treatment is partly due to the theoretical risk that conservative management in plaster may result in subsequent knee, ankle, and subtalar joint osteoarthritis.
Two theoretical mechanisms exist by which osteoarthritis, pain, or disability could complicate treatment in plaster. The first is that conservative treatment is associated with a higher incidence of fracture malunion than operative fracture fixation. ${ }^{2-8}$ Fracture malunion disrupts force transmission across adjacent joints, ${ }^{9}$ and this may cause pain, osteoarthritis, and disability. Some surgeons now consider the acceptable limits of fracture malalignment to be less than $5^{\circ}$ of angulation in any plane, $10^{\circ}$ of rotation, and $5 \mathrm{~mm}$ of shortening. ${ }^{8}$ However, at present there is no consensus ${ }^{10}$ and many surgeons accept greater degrees of malalignment.

The second theoretical reason why osteoarthritis, pain, and disability may complicate conservative treatment is that the ankle, subtalar, and sometimes the knee joint are immobilised in the plaster cast until fracture union (mean time to union $=16$ weeks). ${ }^{2}$ Joint immobilisation can cause stiffness ${ }^{2}$ and may also damage articular cartilage. ${ }^{11-13}$

Alternatively, the development of osteoarthritis may be related to injury factors rather than treatment factors. The former include injury to articular cartilage or the soft tissues surrounding a joint. If this is the case, then treatment methods cannot be blamed for subsequent joint degeneration.

Although the risks of osteoarthritis after conservative treatment of tibial shaft fracture are regularly reiterated, there is no convincing clinical evidence to support this. ${ }^{14}{ }^{15}$ Very little research has been carried out, and studies to date have investigated only a few subjects. ${ }^{16-19}$ The longterm sequelae from tibial shaft fractures treated in the 1950 s and 60 s need to be assessed. We therefore investigated the longterm morbidity of conservatively managed tibial shaft fractures by comparing patients who had sustained such a fracture with subjects who had not, but who were otherwise similar. Because the most relevant outcome for many people is pain, with or without a diagnosis of radiographic osteoarthritis, ${ }^{20}$ this study aimed to investigate this as the primary outcome.

\section{Methods}

Approval for this study was obtained from the local research ethics committees. The plaster room ledger of the Nottingham General Hospital had records of 1400 adults who sustained tibial shaft fractures between 1954 and 1967 (minimum follow up $=27$ years). 
During this period, most isolated tibial shaft fractures were treated conservatively in plaster.

The Nottingham hospitals' medical records patient database, the Nottinghamshire Family Health Services Authority database, and the General Hospital master card index were used to identify the GPs and the addresses of surviving patients in Nottinghamshire. The National Health Service Central Register traced those living outside Nottinghamshire, and provided cause of death for those who had died. GPs of surviving patients were contacted to request permission to approach their patients. For dead patients, age, sex, and cause of death were checked to ensure no potential bias was introduced by their exclusion.

Four subjects matched for age, sex and GP were obtained for each member of the study group with a tibial shaft fracture. These were selected using the appropriate family health services authority database.

A questionnaire was sent to all subjects. This included basic personal and demographic questions, questions on knee pain ${ }^{2122}$ based on the national health and nutrition examination survey (NHANES), questions concerning leg injuries, operations, and immobilisation, and the short form 36 (SF-36) health status questionnaire. ${ }^{23-25} \mathrm{~A}$ reminder letter and second questionnaire were sent after three weeks to those who did not return their first questionnaire.

Knee pain was the primary outcome used. Subjects were categorised as having knee pain according to criteria defined by Maurer and McAlindon et $a l^{21}{ }^{22}$ Subjects were considered to be positive for knee pain if they had ever had pain in or around a knee on most days for at least a month, and if they had experienced that pain during the last year. Self reported doctor's diagnosis of osteoarthritis; ability to climb a flight of stairs, ability to walk 100 yards, ability to bend, kneel, or stoop (each categorised as "limited a lot", "limited a little" and "not limited at all"); and the SF-36 physical functioning score were selected in advance as secondary outcome measures. The proportions of tibial shaft fracture subjects reporting knee pain and a self reported GP diagnosis of osteoarthritis were compared with the proportions of nonfracture patients using corrected MantelHaenszel $\chi^{2}$ tests. ${ }^{26}$ Conditional logistic regression was used to adjust for potential confounders (age, sex, body mass index, previous or subsequent knee injury-including sporting injury, smoking status and SF-36 mental health score-which may influence self reported measures). Associations between exposure status and ability to climb stairs, ability to walk 100 yards, ability to bend, kneel, or stoop (limited versus not limited) and SF-36 physical functioning score (< median versus $\geqslant$ median) were compared using corrected Mantel-Haenszel $\chi^{2}$ tests. ${ }^{26}$

\section{Results}

Exactly 1400 patients who had suffered a tibial shaft fracture were identified from plaster room records. Of these patients, $849(61 \%)$ were traced, but no family health service authority

\section{KEY POINTS}

- Tibial shaft fracture 30 years ago is associated with greater prevalence of associated knee pain, osteoarthritis, and disability now.

- There is greater difficulty with some everyday physical activities such as climbing a flight of stairs and bending, kneeling, or stooping.

- This may be due to injury related factors or treatment related factors.

could be found for 30, 5 were not registered with a GP, and 3 had emigrated. These 38 patients were therefore not contacted and were excluded from further analysis. Of the remaining 811 patients, 239 (29\%) had died. The causes of death were: neoplasm 69 (29\%) $(\mathrm{ICD}=140-239)$, ischaemic heart disease 58 $(24 \%)$, and disease of the musculoskeletal system and connective tissue $1(<1 \%)$.

Approval was sought from the GP to contact the remaining 572 patients and 2285 comparison subjects (for 3 of the tibial shaft fracture patients only 3 comparison subjects could be found). This permission was not given for 30 subjects (seven with tibial shaft fractures, 23 comparison subjects). The remaining 2827 subjects were contacted, and 1971 returned a questionnaire. The response rate was therefore $70 \%$. The response rate of the comparison subjects ( 157 of $2262,70 \%$ ) was almost identical to that of the tibial shaft fracture subjects (398 of 565, 70\%).

The 398 tibial shaft fracture patients had a mean (SD) age of $62.9(10.6)$ and the 1573 comparison subjects had mean age $63.6(10.8)$. The mean (SD) body mass index (BMI) was 26.0 (3.9) for tibial shaft fracture patients and 25.7(4.0) for the comparison group. The proportion of women returning questionnaires was only slightly higher in the tibial shaft fracture group $(19 \%)$ than in the non-fracture group $(17 \%)$. For the tibial shaft fracture patients, the length of time since their fracture ranged between 27 and 41 years (mean 35 years).

Only 59 subjects did not complete the knee pain question (14 fracture subjects, 45 comparisons). A total of 156 of $384(40.6 \%)$ fracture subjects reported knee pain compared with 496 of $1528(32.5 \%)$ comparison subjects (Mantel-Haenszel summary $\chi^{2}=8.73$, $\mathrm{p}=0.003)$. In total, 78 of $398(19.6 \%)$ fracture subjects and 201 of 1573 (12.8\%) comparison subjects reported a diagnosis of osteoarthritis from their GP (Mantel-Haenszel summary $\left.\chi^{2}=6.12, p=0.013\right)$.

To adjust for potential confounders, conditional logistic regression was used on two outcome measures: knee pain and self reported GP diagnosis of osteoarthritis. After adjusting for age, sex, body mass index, smoking, and mental health, subjects who had suffered a tibial shaft fracture had $23 \%$ higher odds of knee pain than the others (odds ratio 1.23 $95 \%$ confidence interval $(95 \% \mathrm{CI}) 1.00,1.51$ $\mathrm{p}=0.047)$. With the outcome of reported GP 
Table 1 Proportion of subjects reporting knee pain and a GP diagnosis of osteoarthritis according to whether they had a tibial shaft fracture

\begin{tabular}{llll}
\hline & Yes & No & $\begin{array}{l}\text { Odds ratio }{ }^{*}(95 \% \\
\text { confidence interval }) \\
\text { p value }\end{array}$ \\
\hline $\begin{array}{l}\text { Knee pain: } \\
\quad \text { Confirmed tibial shaft fracture }\end{array}$ & $156(40.6 \%)$ & $228(59.4 \%)$ & \\
$\quad$ No fracture & $496(32.5 \%)$ & $1032(67.5 \%)$ & $\begin{array}{l}1.23(1.00,1.51) \\
\mathrm{p}=0.047\end{array}$ \\
$\begin{array}{l}\text { Osteoarthritis: } \\
\quad \text { Confirmed tibial shaft fracture } \\
\text { No fracture }\end{array}$ & $78(19.6 \%)$ & $320(80.4 \%)$ & $1.46(1.08,1.97)$ \\
& $201(12.8 \%)$ & $1372(87.2 \%)$ & $\mathrm{p}=0.016$
\end{tabular}

* Odds ratios from conditional logistic regression adjusting for age, sex, body mass index, previous or subsequent knee injury, smoking, and mental health.

Where numbers fail to sum to total in study this is due to incomplete questionnaires.

Table 2 Limitations in climbing stairs, walking 100 yards, and bending, kneeling or stooping in subjects with or without a tibial shaft fracture

\begin{tabular}{lllll}
\hline & Limited & & \\
\cline { 2 - 5 } & Alot & A little & Not at all & p value \\
\hline Climbing one flight of & & & & \\
stairs: & & & & \\
Confirmed fracture & $57(15.4 \%)$ & $101(27.4 \%)$ & $211(57.2 \%)$ & \\
$\quad$ No fracture & $175(12.0 \%)$ & $303(20.7 \%)$ & $985(67.3 \%)$ & $\mathrm{p}=0.001$ \\
Bending, kneeling, & & & & \\
$\quad$ stooping: & $102(26.9 \%)$ & $141(37.2 \%)$ & $136(35.9 \%)$ & \\
$\quad$ Confirmed fracture & $316(21.0 \%)$ & $533(35.5 \%)$ & $654(43.5 \%)$ & $\mathrm{p}=0.001$ \\
$\quad$ No fracture & & & & \\
Walking 100 yards: & $35(9.8 \%)$ & $57(16.0 \%)$ & $264(74.2 \%)$ & \\
$\quad$ Confirmed fracture & $118(8.3 \%)$ & $181(12.8 \%)$ & $1117(78.9 \%)$ & $\mathrm{p}=0.124$ \\
No fracture &
\end{tabular}

* Corrected Mantel-Haenszel $\chi^{2}$ test $^{26}$ (limited versus not limited)

Where numbers do not add up to the total in the study, this is due to incomplete questionnaires.

diagnosis of osteoarthritis, the odds ratios were 1.46 (95\% CI 1.08, 1.97, p=0.016). Proportions in each group and adjusted odds ratios are shown in table 1.

The numbers of subjects who had limited ability to climb a flight of stairs, to bend, kneel or stoop, and to walk 100 yards are shown in table 2. The median SF-36 physical functioning score for both groups was 80 (interquartile range 50-95). For the fracture subjects it was 77.5 (45-95) and for the comparison subjects it was 85 (55-95). The SF-36 physical functioning score was significantly lower for the fracture subjects than the comparisons (using $<80$ versus $80+$, Mantel-Haenszel summary $\chi^{2}=5.55$, $\mathrm{p}=0.019)$.

\section{Discussion}

These results indicate that people who sustained tibial shaft fractures between 1954 and 1967, when most of these fractures were treated conservatively, are now more likely than other people to suffer knee pain. In addition, they are more likely to have a self reported GP diagnosis of osteoarthritis. After adjusting for possible confounders (age, sex, body mass index, previous or subsequent knee injury, smoking and SF-36 mental health score), this result remained unchanged. The $95 \% \mathrm{CI}$ is wide and the magnitude of the association is small, but sufficiently large to cause concern given that tibial shaft fracture is a common injury. Everyday physical activities were more limited in subjects who had sustained a tibial shaft fracture. In the fracture group, $42.8 \%$ were limited "a little" or "a lot" in climbing stairs, and $64.1 \%$ were similarly limited in bending, kneeling or stooping compared with
$32.7 \%$ and $56.5 \%$ of the non-fracture subjects respectively.

It is anticipated that our plaster room records identified almost everyone who had sustained tibial shaft fractures during this period as virtually all patients with conservatively treated tibial shaft fractures require at least one plaster change during the course of their treatment. Unfortunately, the clinical notes and operation records for this period were unavailable. Results are based on 398 of the original 1400 subjects identified from plaster room records. Though it is possible that untraced patients were the most mobile, given the time delay they are more likely to be missing at random and therefore not a source of bias. The causes of death for the tibial shaft fracture subjects showed no obvious pattern that suggests bias could have been introduced by their exclusion. Among those who were traced alive, and contacted, the response rate was $70 \%$, which is respectable for a postal questionnaire. Our results are unlikely to be due to differences in body mass index, previous or subsequent knee injuries (which include any sporting injury sustained), smoking status, or age between the groups, or by the small imbalance in the sexes. Multivariate analysis adjusting for these factors supported the univariate findings. It is also unlikely that bias could have been introduced by a knowledge of the aims of the study as the aims were explained in only general terms.

Previous studies which have specifically investigated whether fracture malunion results in subsequent osteoarthritis of adjacent joints fail to agree on whether a relationship exists. ${ }^{16-19}$ Although the follow up periods of these studies were long, the numbers of fractures studied were small, with only 14,37 , 22 , and 28 identified fractures being assessed respectively.

We compared 398 tibial fracture subjects treated conservatively with subjects without a fracture and found that the former are more likely to suffer knee pain and report a GP diagnosis of osteoarthritis. The only detectable differences between the two groups were that subjects in one group had previously sustained a tibial shaft fracture and that this had been managed conservatively. There are four possible explanations for this association. Firstly, the increased prevalence of disability and knee pain may be due to the treatment given, either because of fracture malunion or joint immobilisation. Secondly, there may be an injury to the knee joint at the same time as the tibia is fractured-which itself could predispose to pain or osteoarthritis (eg rupture of a knee ligament). Thirdly, it may be due to other factors associated with fractures such as soft tissue damage, which cannot be rectified. Fourthly, it may be a result of shared risk factors (eg sporting activities which may accelerate cartilage wear and also increase the risk of tibial shaft fracture). However, in the absence of injury, low levels of sporting activity are unlikely to have a large association with osteoarthritis ${ }^{27}$ or to greatly increase the risk of fracture and in this study knee injury from any cause 
(including sport) was controlled for in the logistic regression.

If the association which we have shown is due to treatment factors (malunion or immobilisation) then the morbidity of these fractures might have been reduced by altering the treatment. If it is due to one of the other suggested mechanisms, then a change of treatment policy would be unlikely to affect the outcome.

A direct comparison between conservative management and operative fixation has not been made. However, a randomised controlled trial or even an observational comparison of these two treatments does not seem practicable because of the time period over which effects may develop. Before the detected morbidity in these tibial shaft fractures can be attributed to their conservative management it will be necessary to examine the degree of malunion, the period of immobilisation, and the distribution and severity of osteoarthritis for evidence of a dose-response relationship or of a threshold effect. If the amount of knee pain and osteoarthritis increased with the amount of malunion, then this would help separate the effects of malalignment from those of immobilisation of the leg in plaster, concomitant injury, or other confounding factors. The size of the effect found lends justification to further work examining the causes of the association.

The most important outcome for a patient is whether they have pain or disability, ${ }^{20}$ and hence knee pain is our primary outcome. In general practice there may be a tendency to label knee pain as "osteoarthritis" without seeking radiological confirmation. We consider this weaker outcome to be secondary to knee pain, and as both are self reported, they may be associated. Results should be interpreted with this in mind. Radiograms provide direct evidence of structural change and they can identify other reasons for secondary osteoarthritis such as a previous tibial plateau fracture. However, pain and disability affecting the performance of daily activities are the more relevant outcomes for most people, and hence the more pragmatic measures.

Most tibial shaft fractures occur in young people, and we have shown an association between tibial shaft fractures (all managed conservatively) and knee pain later in life. These young people treated over 25 years ago now have more disability and may require a higher level of care than their peers. If this disability is due to treatment rather than injury factors, it is potentially preventable through changes in fracture management. Further studies involving $x$ ray assessment of these former patients are justified in order to clarify the nature of this association.

We thank the staff in the Queen's Medical Centre Medical Records for help finding the original records, Nottinghamshire Family Services Authority and Kathy Smith for assistance with tracing subjects in Nottinghamshire and secretarial support. We also thank the National Health Service Central Register and the following family health services authorities for tracing patients currently living outside Nottinghamshire: Bedfordshire, Avon, currently living outside Nottinghamshire: Bedfordshire, Avon, Derbyshire, Devon, Durham, Dudley, Leicestershire, Lincoln-
shire, Norfolk, Northumberland, Stockport, Staffordshire, Whire, Norfolk, Northumberland, Stockport, Staffordshire, Wiltshire and Solihull. We are grateful to the GPs of patients
taking part in this study, and to the patients themselves for comtaking part in this study, and
pleting our questionnaire.

Funding: Arthritis \& Rheumatism Council for Research. Conflicts of interest: none.

1 Hooper GJ, Keddell RG, Penny ID. Conservative management or closed nailing for tibial shaft fractures. ment or closed nailing for tibial shaft fractures. A 5 .

2 Nicoll EA. Fractures of the tibial shaft. A survey of 705 cases. F Bone Foint Surg 1964;46:373-87.

3 Ruedi T, Webb JK, Allgower $M$. Experience with the dynamic compression plate (DCP) in 418 recent fractures of the tibial shaft. Injury 1976;7:252-7.

4 Johner R, Wruhs O. Classification of tibial shaft fractures and correlation of results after rigid internal fixation. Clin Orthop 1983;178:7-25.

5 Bone LB, Johnson KD. Treatment of tibial fractures by reaming and intramedullary nailing. $\mathcal{F}$ Bone foint Surg 1986;68:877-87.

6 Oni OOA, Hui A, Gregg PJ. The healing of closed tibial shaft fractures. The natural history of union with closed treatment. $\mathcal{F}$ Bone foint Surg 1988;70:787-90.

7 Prince HG, Webb JK, Christodoulou A. Tibial fractures: primary AO plating or functional cast bracing? $\mathcal{F}$ Bone foint primary AO plating

8 Court-Brown CM, Christie J, McQueen MM. Closed Court-Brown CM, Christie J, McQueen MM. Closed
intramedullary tibial nailing. $\mathscr{f}$ Bone foint Surg 1990;72: 605-11.

9 McKellop HA, Sigholm G, Redfern FC, Doyle B, Sarmiento A, Luck JV. The effect of simulated fracture angulations of the tibia on cartilage pressures in the knee joint. F Bone foint Surg 1991;73:1382-91.

10 Bridgman SA, Baird K. Audit of closed tibial fractures: what is a satisfactory outcome? Injury 1993;24:85-9.

11 Salter RB, Field P. The effects of continuous compression on living articular cartilage. An experimental investigation. F Bone Foint Surg 1960;42:31-49.

12 Brower TD, Akahoshi Y, Orlic P. The diffusion of dyes through articular cartilage in vivo. $\mathcal{F}$ Bone foint Surg 1962; 44:456-463.

13 Enneking WF, Horowitz $M$. The intra-articular effects of immobilisation on the human knee. $\mathcal{F}$ Bone foint Surg 1972; 54:973-85.

14 Ross ERS. Post-traumatic osteo-arthritis - inevitable, preventable or more medical mythology? Int $\mathcal{f}$ Orthop Trauma 1991;1:179-80.

15 Russell TA, Taylor JC, LaVelle DG. Fractures of the tibia and fibula. In: Rockwood CA, Green DP, Bucholz RW, eds. Rockwood and Green's fractures in adults. 3rd ed. Philadelphia: JB Lippincott Company, 1991:1915-82.

6 Kettelkamp DB, Hillberry BM, Murrish DE, Heck DA. Degenerative arthritis of the knee secondary to fracture malunion. Clin Orthop 1988;234:159-69.

17 Merchant TC, Dietz FR. Long-term follow-up after fractures of the tibial and fibular shafts. $\mathcal{F}$ Bone foint Surg 1989;71:599-606.

18 Kristensen KD, Kiaer T, Blicher J. No arthrosis of the ankle 20 years after malaligned tibial-shaft fracture. Acta Orthop Scand 1989;60:208-9.

19 Puno RM, Vaughan JJ, Stetten ML, Johnson JR. Long-term effects of tibial angular malunion on the knee and ankle effects of tibial angular malunion on the
joints. F Orthop Trauma 1991;5:247-54.

20 Hadler NM. Knee pain is the malady - not osteoarthritis. Ann Int Med 1992;116:598-9.

21 Maurer K. Basic data on arthritis. Knee, hip, and sacroiliac joints in adults ages 25-74 years. In: Vital and health statistics. Data from the national health survey. Series 11. No. 213. London: DHEW Publications. 1979

22 McAlindon TE, Cooper C, Kirwan JR, Dieppe PA. Knee pain and disability in the community. Brf Rheumatol 1992; 31:189-92.

23 Brazier JE, Harper R, Jones NMB, O'Cathain A, Thomas KJ, Usherwood T, Westlake L. Validating the SF-36 health survey questionnaire: new outcome measure for primary care. BMF 1992;305:160-4.

24 Jenkinson C, Coulter A and Wright L. Short form 36 (SF36) health survey questionnaire: normative data for adults of working age. BMF 1993;306:1437-40.

25 Garratt AM, Ruta DA, Abdalla MI, Buckingham JK and Garratt AM, Ruta DA, Abdalla MI, Buckingham JK and Russell IT. The SF- 36 health survey questionnaire: an outcome measure suitable

26 Breslow NE, Day NE. Statistical methods in cancer research. Volume 1 - the analysis of case-control studies. Lyon: International Agency for Research on Cancer, 1980: 176-82.

27 Lane NE. Exercise: a cause of osteoarthritis. $\mathcal{f}$ Rheumatol 1995;43 suppl:3-6. 